\title{
MAPEAMENTO DOS INDICADORES DE IMPACTO AMBIENTAL E MANEJO NA TRILHA DO PARQUE NACIONAL DO VIRUÁ - RORAIMA
}

\author{
MAPPING INDICATORS OF ENVIRONMENTAL IMPACT AND MANAGEMENT ON THE TRAIL OF THE \\ VIRUÁ NATIONAL PARK - RORAIMA
}

\section{MAPEO DE LOS INDICADORES DE IMPACTO AMBIENTAL Y GESTIÓN EN EL SENDERO DEL PARQUE NACIONAL VIRUÁ - RORAIMA}

Paulo Roberto Teixeira

Professor efetivo do curso de Turismo na Universidade Estadual de Roraima (UERR) Mestre em Turismo - Universidade de Caxias do Sul (UCS) prt.teixeira@gmail.com

Rita Lourdes Michelin

Professora efetiva do curso de Turismo na Universidade Estadual de Roraima (UERR) Mestre em Turismo - Universidade de Caxias do Sul (UCS) rita.michelin@gmail.com

Data de Submissão: 31/05/2016

Data de Aprovação: 06/03/2017

RESUMO: O Parque Nacional do Viruá está localizado no Estado de Roraima e se caracteriza como uma Unidade de Conservação de Proteção Integral. O parque possui atributos geográficos e ecológicos que lhe conferem vocação especial para a visitação e turismo na Amazônia, destacando-se pela diversidade da fauna e flora e pelo extenso mosaico de vegetação de Campinaranas. $O$ estudo visou à identificação e à mensuração de indicadores de impacto ambiental que pudessem ser utilizados para avaliar e monitorar os impactos resultantes da ação antrópica na trilha. A metodologia aplicada utilizou os seguintes instrumentos: GPS, clinômetro e softwares de sensoriamento remoto. A trilha foi dividida em 24 trechos, dos quais foram avaliados: declividade, largura e profundidade da trilha, além de danos aos recursos naturais e infraestrutura, problemas de drenagem, número de trilhas não oficiais e quantidade de lixo. Os resultados demonstraram que o local não apresenta impactos ambientais relevantes, no entanto foi identificada falta de infraestrutura, como placas de sinalização e estruturas de conforto e segurança ao visitante, como bancos e corrimão. Com esse estudo se espera um monitoramento constante dos impactos na trilha e a adequada identificação de pontos de manejo para que a mesma possa ser utilizada de forma sustentável pela atividade turística e de pesquisa.

PALAVRAS CHAVE: Turismo. Impacto Ambiental. Parque Nacional do Viruá - RR.

ABSTRACT: The Viruá National Park is located in the State of Roraima and is characterized as an Integral Protection Conservation area. The park has geographical and ecological attributes that give it special vocation for visitation and tourism in the Amazon, highlighting the diversity of fauna and flora and the extensive mosaic Campinaranas vegetation. The study aimed at identifying and measuring environmental impact indicators that could be used to assess and monitor the impacts of human activities on the track. The methodology used the following instruments: GPS, clinometer and remote sensing software. The trail is divided into 24 sections, in which were evaluated on: slope, width and depth of the track, and damage to natural resources and infrastructure, drainage problems, number of unofficial trails and amount of waste. The results demonstrated that the site does not present significant environmental impact, however, the lack of infrastructure is identified as signposts, comfort and security structures for the visitor, such as banks and handrails. Expected with this study is constant monitoring of the impact on the track and the proper identification of management points so that it can be used sustainably for tourism and research.

KEYWORDS: Tourism. Environmental impact. National Park Viruá - RR.

RESUMEN: El Parque Nacional Viruá se encuentra en el Estado de Roraima y se caracteriza como una Unidad de Conservación de Protección Integral. El parque cuenta con atributos geográficos y ecológicos que le dan especial interés para la visitación y el turismo en la Amazonía, destacándose por la diversidad de la fauna y la flora y por el extenso mosaico de vegetación de campinaranas. El estudio tuvo el objetivo de identificar y medir los indicadores de impacto 
ambiental que podrían utilizarse para evaluar y monitorear los impactos de las actividades humanas en el sendero. La metodología aplicada utiliza los siguientes instrumentos: GPS, clinómetro y software de detección remota. El sendero fue dividido en 24 secciones, en las que se evaluaron: pendiente, anchura y profundidad del sendero, además de daños a los recursos naturales y a la infraestructura, los problemas de drenaje, el número de senderos no oficiales y la cantidad de residuos. Los resultados demostraron que el sitio no presenta impactos ambientales significativos; sin embargo, se identificó falta de infraestructura tal como señales de tráfico y estructuras de seguridad y comodidad para el visitante, como bancos y pasamanos. Con este estudio se espera una monitorización constante de los impactos sobre el sendero y la correcta identificación de los puntos de administración para que el mismo pueda ser utilizado de forma sostenible para el turismo y la investigación.

PALABRAS CLAVE: Turismo. Impacto ambiental. Parque Nacional Viruá - RR.

\section{INTRODUÇÃO}

Floresta Amazônica desperta o interesse de muitas pessoas em várias
partes do mundo, seja por sua riqueza natural, seja por sua beleza
e atrativos naturais. Essa em particular atrai um elevado número de visitantes todos os anos, a fim de conhecer seus rios, fauna e flora. Por outro lado, os impactos causados pelo desmatamento e queimadas têm aumentado constantemente desde 1991, variando de acordo com as mudanças relacionadas às forças econômicas e, em geral, os grandes e médios fazendeiros respondem pela grande maioria da atividade do desmatamento (FEARNSIDE, 2006).

A implantação de áreas protegidas (unidades de conservação, terras indígenas e APPs e Reservas Legais do código florestal) é uma das medidas encontradas para preservar partes do ambiente natural, principalmente no bioma amazônico, que sofre constantes impactos. As unidades de conservação, de maneira particular, podem se tornar importantes atrativos turísticos para os locais onde estão inseridos, uma vez que visam à conservação e à preservação dos recursos naturais, bem como a sua utilização consciente através da educação e da interpretação ambiental. Além disso, as questões ambientais podem ser trabalhadas em conjunto com elementos da cultura local, reforçando os laços com as comunidades de entorno.

No estado de Roraima os segmentos do turismo ligados aos recursos naturais são os que mais se destacam, no caso do Parque Nacional do Viruá atualmente o segmento do turismo ecocientífico (de pesquisa) é o que atrai mais visitantes, seguido do turismo de observação de aves. Ambos os segmentos caracterizam-se por um turismo alternativo, ou seja, que é realizado por grupos 
pequenos, indivíduos preocupados com questões ambientais e socioculturais, e que buscam conhecer locais pouco visitados.

O turismo voltado aos ambientes naturais, que prega seu uso de maneira responsável e a inclusão das comunidades locais no processo de desenvolvimento, poderia contribuir como uma dessas alternativas (RODRIGUES, 2003). O desenvolvimento proporcionado pelo turismo deve visar ao crescimento econômico, à valorização da cultura local, à não geração de danos e à maximização dos benefícios, sendo assim, harmônico por ocorrer de forma responsável.

Nesse sentido, faz-se necessário compreender de que maneira a atividade turística e de pesquisa que ocorre no Parque Nacional do Viruá pode interferir no local, nesse caso, na trilha. Para tal, a identificação de indicadores de impacto foi a primeira medida, pois com eles se podem acompanhar as mudanças que ocorrem na trilha em função da constantes visitas ao local. Foram utilizadas metodologias de Mitraud (2003), além de Lobo e Simões (2009).

\section{AS TRILHAS E OS IMPACTOS AMBIENTAIS}

As distintas formas de ação do ser humano sobre o meio ambiente ao longo da sua evolução são hoje reconhecidas como tema essencial para a pesquisa científica, sob a responsabilidade de se buscar soluções ou alternativas de uso humano compatíveis com a conservação dos recursos naturais e culturais. Para Ferretti (2002), o ser humano é parte, causa e consequência das modificações que $\mathrm{o}$ ambiente vem sofrendo.

A evidente destruição dos ecossistemas pela ação antrópica tem colocado em risco a sobrevivência das diferentes formas de vida na Terra. A interação entre os recursos naturais e o turismo é, portanto, invariável, resultando na busca de um ponto de equilíbrio entre seu uso e proteção, pela própria perpetuação da atividade turística (RUSCHMANN, 2003). A demanda turística pelos recursos naturais é crescente diante da expansão das formas de turismo ligadas à natureza e toda visitação nesses locais causa algum tipo de impacto. Para isso é importante adotar medidas de identificação e controle para assegurar o uso sustentável desses ambientes. Segundo Mitraud (2003), para se resolver um problema, deve-se isolar suas causas, elaborar estratégias para eliminá-las ou minimizá-las e, finalmente, estabelecer metas e acompanhar a implementação, até que tenham sido atingidas as metas ou o problema tenha sido resolvido. 
Impacto ambiental é definido pelo Conselho Nacional de Meio Ambiente (CONAMA) como qualquer alteração das propriedades físicas, químicas e biológicas do meio ambiente, causada por qualquer forma de matéria ou energia resultante das atividades humanas. Os impactos decorrentes das visitações podem ser verificados no solo, nas águas, na flora e na fauna. Quando se trata do solo, Andrade (2003) afirma que existem dois fatores de alteração decorrente do uso desse: compactação e erosão. Acrescenta que, quando as pessoas pisam, há um efeito mecânico direto que provoca a exposição das raízes das árvores, o que as torna vulneráveis a doenças e até a quedas e diminui a capacidade de retenção de água.

Sendo assim, a erosão do solo expõe as raízes das plantas, dificultando sua sustentação, além causar acidentes às pessoas que estão visitando o local. Esse é um dos problemas mais graves e pode ser, em alguns casos, irreversível, e a recuperação dessas áreas é extremamente onerosa e não garante a completa reabilitação do local (LOBO; SIMÕES, 2009). Outros impactos associados à vegetação seriam: diminuição da cobertura vegetal, mudança na diversidade de espécies, e o impacto sobre as árvores que ficam mais próximas à trilha, as quais podem sofrer quebra de galhos e inscrições.

Uma trilha pode ser dividida em pequenas áreas, o que facilita seu estudo e manejo. O Instituto Florestal (2008) define que toda área sob influência da utilização da trilha é chamada corredor da trilha e sua porção central é a superfície de pisoteio (Figura 1). A porção contígua à superfície de pisoteio é a área marginal, que deve ter aproximadamente $80 \mathrm{~cm}$ de cada lado.

Figura 1: Esquema das partes que compões uma trilha.

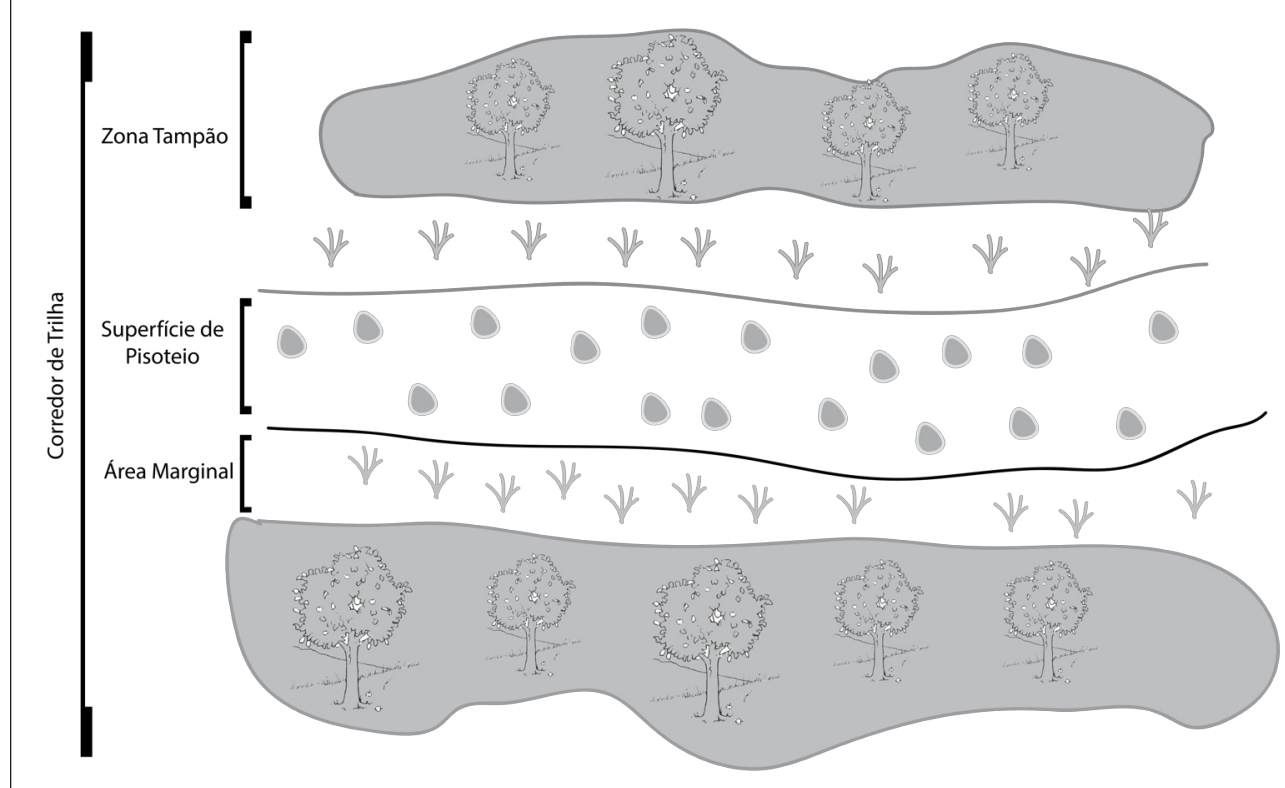


Fonte: Adaptado de Andrade, 2008.

Inúmeras trilhas recreativas são sujeitas a forças de degradação induzida por natureza e uso recreativo e essa degradação é uma grande preocupação para muitos gestores. Uma gestão profissional dessas trilhas requer informações objetivas sobre as condições dos recursos do piso da trilha, incluindo características físicas, avaliação de impactos de recursos e trabalhos de manutenção necessários (MARION; LEUNG, 2011).

Esses impactos poderiam ser, em grande parte, reduzidos se técnicas de manejo e controle fossem efetivamente implementadas. Vale lembrar, também, que "nem todas as intervenções do turismo se traduzem, necessariamente, na agressão ou degradação do meio ambiente natural" (RUSCHMANN, 2003, p.56). Portanto, ao se relacionar os impactos causados pela visitação, há de se ter o cuidado em relacionar somente os impactos causados pelo turismo e não os já existentes resultantes de outras causas.

\section{ÁREA DE ESTUDO}

O Parque Nacional do Viruá (PNV) foi criado em 29 de abril de 1989 e está localizado no estado de Roraima no município de Caracaraí a 188 km da capital, Boa Vista. A via de acesso principal se dá pela BR-174, que liga a cidade de Manaus (AM) a Venezuela (Figura 2), sendo também possível o acesso fluvial através do rio Branco e Anauá.

Figura 2: Mapa de localização do Parque Nacional do Viruá - Caracaraí - RR.

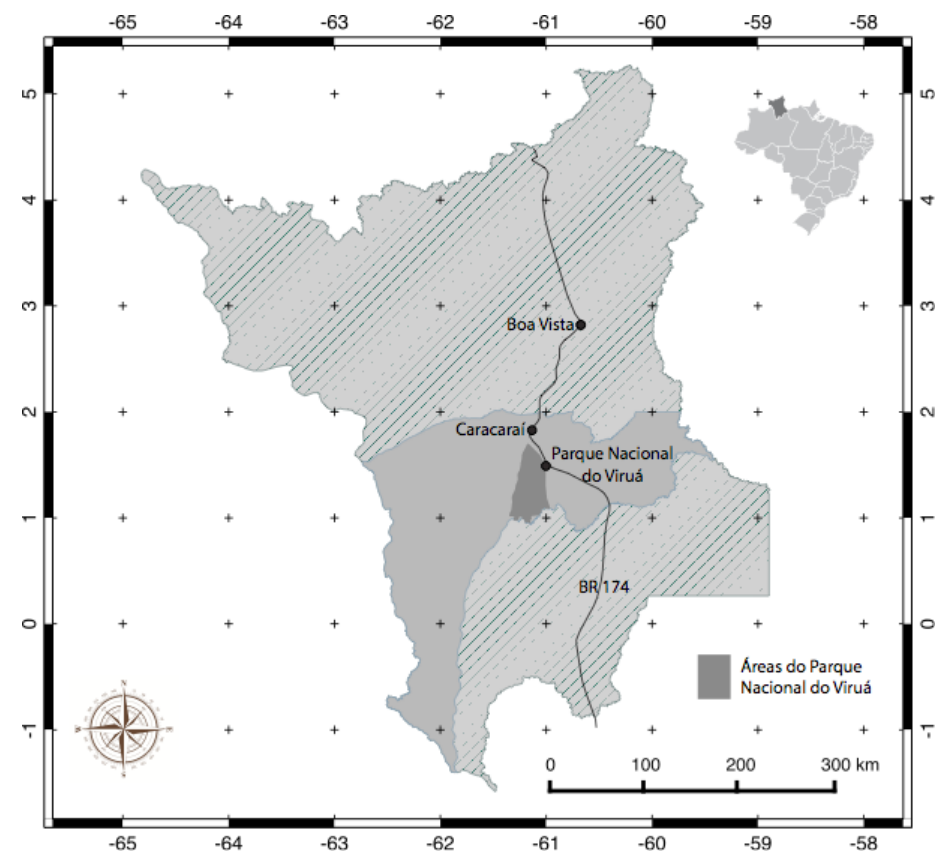


Fonte: Elaborado pelo autor com dados do IBGE.

O Parque abrange uma área de 227 mil hectares e sua paisagem é muito heterogênea, compreendendo mosaicos de diversas fisionomias de florestas, campinas e campinaranas, inúmeras lagoas, extensos banhados, buritizais e chavascais, em ambientes marcados por fortes inundações sazonais, constituindo um verdadeiro complexo de pantanal com alto endemismo. Sua criação foi devido a um acordo internacional firmado no âmbito da Convenção da Diversidade Biológica, com meta definida a proteger dez por cento do território nacional na forma de unidades de conservação de proteção integral (ICMBIO, 2010).

Com relação à vegetação e aos solos, se caracteriza por formações pioneiras arbustivas e campinarana arbórea e arbustiva sobre espodossolos cárbicos e ferrocárbicos em áreas abaciadas e argissolos amarelos alumínicos típicos e acinzentados alumínicos arênicos nos terraços. Devido à predominância de areia, apresenta terras inaptas para o uso com lavouras (CPRM, 2002).

A geomorfologia da região é classificada como pediplana, caracterizada por terrenos planos, com dissecação variando de fraca a muito fraca, associada a áreas ocasionalmente inundáveis nos períodos chuvosos, com trechos alagados por prolongado a permanente período de tempo. A superfície se desenvolve sobre as rochas sedimentares da Formação Içá, em cotas inferiores aos 100 metros, e eventualmente sobre rochas graníticas e alcalinas do Escudo das Güianas, que afloram na superfície sob a forma de relevo residual (CPRM, 2002).

\section{MATERIAIS E MÉTODOS}

O método envolveu, inicialmente, a pesquisa bibliográfica, a fim de sustentar as metodologias utilizadas e reforçar trabalhos existentes na área de trilhas. $O$ mapeamento da trilha foi realizado em abril de 2013 e seguiu quatro etapas com metodologias distintas: largura; profundidade; declividade; impactos e manejo.

A trilha foi mapeada utilizando-se um GPS da marca Garmim, modelo Montana 650, com a configuração UTM WGS 84, as coordenadas obtidas tiveram a precisão média de $3 \mathrm{~m}$. Os dados obtidos com o GPS foram acessados 
e trabalhados nos programas: Garmim Basecamp 4.2.3, Quantum Gis 2.0 e Illustrator CS6.

A trilha possui 1.250 metros, após ser medida, definiu-se que a mesma teria 25 pontos de monitoramento (p0, p1, p2...) com uma distância de 50 metros entre cada um e 24 trechos (T0-1, T1-2, T2-3...), que são os espaços entre os pontos de monitoramento. Essa divisão é importante, pois divide a trilha em setores, o que facilita a identificação de impactos e/ou locais com necessidade de alguma forma de manejo (Figura 3). Cada ponto de monitoramento recebeu uma etiqueta na cor amarela com dados de distância e identificação do ponto correspondente.

Figura 3: Representação da divisão da trilha em setores e pontos.

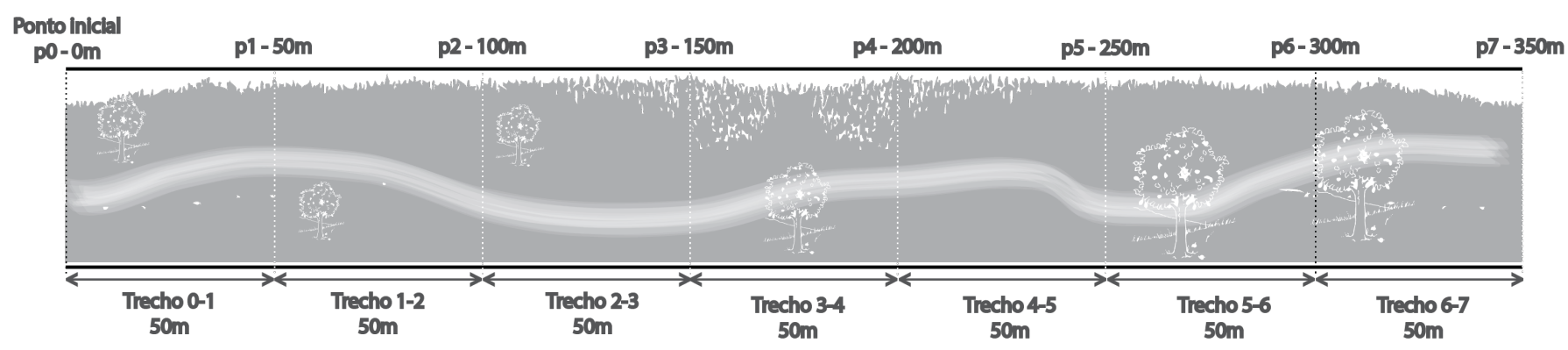

Fonte: Os autores.

A coleta de dados de largura e profundidade foi realizada nos 25 pontos de monitoramento. Já outros indicadores, como: declividade e impactos, foram analisados em toda extensão da trilha, respeitando a divisão por trechos para facilitar o relatório. Para Mitraud (2001, p. 26), "a metragem é necessária não só para o conhecimento da extensão total da trilha, mas para identificar a marcar trechos com características específicas", como locais que necessitem de sinalização, manutenção da trilha em si e até sugestões de paradas.

\section{a) largura, profundidade e declividade}

Em cada ponto foram coletadas três amostras de largura e profundidade, o primeiro no ponto demarcado como 50 metros, outro a 1 metro à frente e outro 1 metro atrás (Figura 4). Foram calculadas as médias em cada ponto e utilizado esse valor como referência. Considerou-se a largura como a distância (em cm) entre as margens do leito da trilha, a qual foi determinada com uma trena.

Figura 4: Metodologia utilizada na medição de largura e profundidade. 


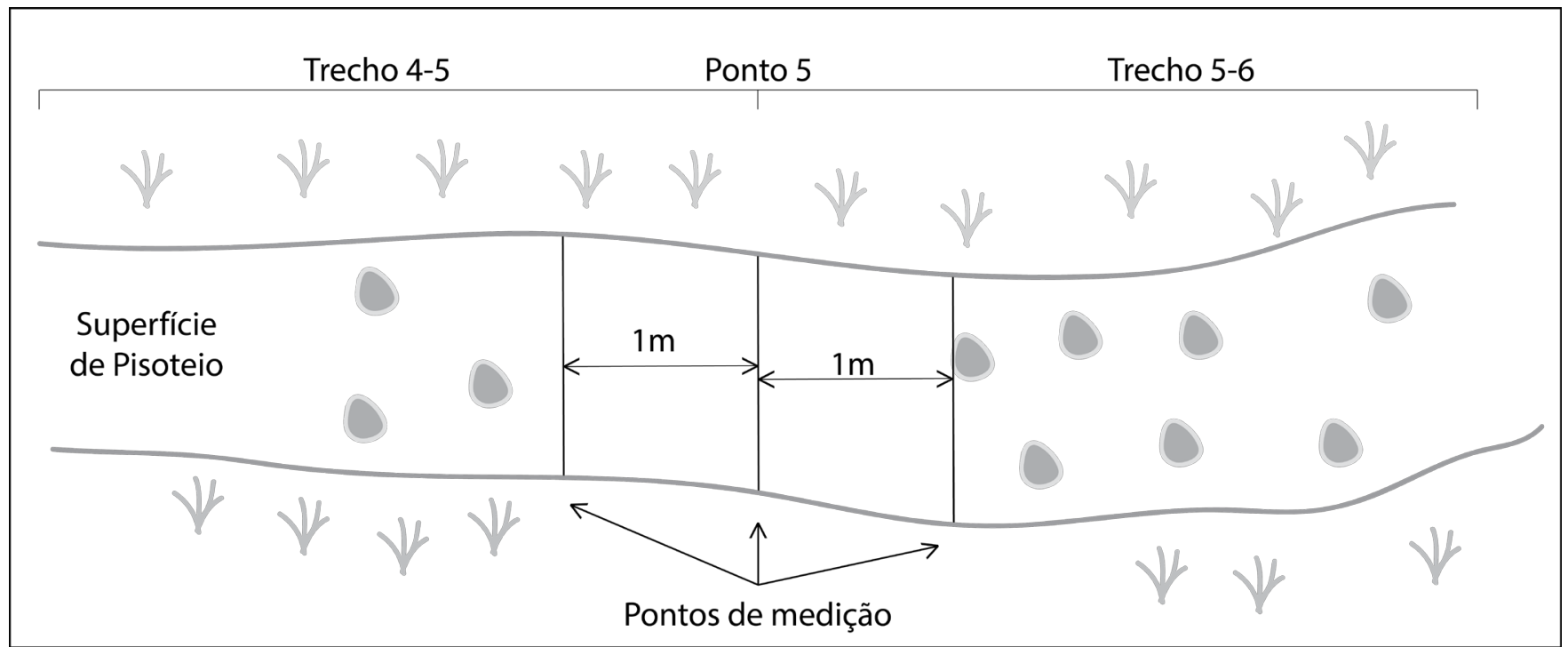

Fonte: Os autores.

Para medição da profundidade foi considerada como a diferença de altura (em $\mathrm{cm}$ ) entre o ponto mais baixo e o ponto mais alto do leito da trilha. Para isto foi fixada, transversalmente à trilha, uma vareta de metal, e desta com uma régua foi medida a distância até o ponto mais profundo do leito da trilha, perpendicularmente à superfí cie do solo. Foram medidos três pontos, seguindo a mesma ordem da medição da largura.

Uma ficha de campo foi elaborada para anotar todos dos dados, nela é possível identificar os pontos com maior impacto, além de suas coordenadas, para posterior análise em ferramentas específicas (Quadro 1).

Quadro 1: Modelo de ficha de campo para coleta de largura e profundidade da trilha.

\begin{tabular}{|c|c|c|c|c|}
\hline \multicolumn{5}{|c|}{ LEVANTAMENTO DE LARGURA E PROFUNDIDADE DE TRILHA } \\
\hline \multirow{2}{*}{\multicolumn{2}{|c|}{$\begin{array}{c}\text { Local: Parna Viruá } \\
\text { Avaliador: }\end{array}$}} & \multicolumn{2}{|c|}{ Trilha: Acesso Grade } & \multirow[t]{2}{*}{ Ficha $\mathrm{n}^{\circ}$ : } \\
\hline & & Data: & Clima: (x ) sol & \\
\hline PONTO & DISTÂNCIA & LARGURA & PROFUNDIDADE & $\begin{array}{c}\text { COORDENADA } \\
\text { (UTM) }\end{array}$ \\
\hline PO & $0 \mathrm{~m}$ & $\begin{aligned} \mathrm{L} 1 & =62 \mathrm{~cm} \\
\mathrm{~L} 2 & =90 \mathrm{~cm} \\
\mathrm{~L} 3 & =55 \mathrm{~cm}\end{aligned}$ & $\begin{array}{l}P 1=11 \mathrm{~cm} \\
P 2=5 \mathrm{~cm} \\
P 3=9 \mathrm{~cm}\end{array}$ & 20 N 722192164850 \\
\hline P1 & $50 \mathrm{~m}$ & $\begin{array}{l}\mathrm{L} 1=90 \mathrm{~cm} \\
\mathrm{~L} 2=60 \mathrm{~cm} \\
\mathrm{~L} 3=70 \mathrm{~cm}\end{array}$ & $\begin{array}{l}P 1=10 \mathrm{~cm} \\
P 2=10 \mathrm{~cm} \\
P 3=8 \mathrm{~cm}\end{array}$ & 20 N 722153164851 \\
\hline P2 & $100 \mathrm{~m}$ & $\begin{aligned} \mathrm{L} 1 & =91 \mathrm{~cm} \\
\mathrm{~L} 2 & =82 \mathrm{~cm} \\
\mathrm{~L} 3 & =81 \mathrm{~cm}\end{aligned}$ & $\begin{aligned} \mathrm{P} 1 & =9 \mathrm{~cm} \\
\mathrm{P} 2 & =5 \mathrm{~cm} \\
\mathrm{P} 3 & =15 \mathrm{~cm}\end{aligned}$ & 20 N 722102164857 \\
\hline
\end{tabular}

Fonte: Os autores.

A declividade foi medida com um clinômetro tipo Abney ao longo de todos os trechos da trilha. Andrade (2008) afirma que essa variável é essencial para 
a determinação de vulnerabilidade à erosão, grau de dificuldade da trilha e descrição de trabalhos de correção na trilha (por exemplo, de acordo com a declividade de um trecho, deverão ser escolhidos determinados métodos de drenagem). Todos os dados coletados nas medições foram anotados em uma ficha de campo para o posterior cálculo de médias (Quadro 2).

A coleta de dados de declividade seguiu a seguinte metodologia. O pesquisador com o clinômetro se posicionava no início da trilha e um segundo pesquisador, com uma vareta de referência, caminhava até a distância máxima que poderia ser visto. Nesse momento era calculado o declive. Esse processo era repetido até que o trecho inicial de 50 metros (T0-1) fosse concluído, para então seguir para o trecho seguinte (T1-2) de 50 metros e assim sucessivamente.

Quadro 2: Modelo de ficha de coleta de declividade.

\begin{tabular}{|c|c|c|c|}
\hline \multicolumn{4}{|c|}{ LEVANTAMENTO DE declividade DE TRILHA } \\
\hline \multicolumn{2}{|c|}{ Local: Parna Viruá } & Trilha: Acesso Grade & Ficha $\mathbf{n}^{\circ}$ : \\
\hline \multicolumn{2}{|c|}{ Avaliador: } & Data: & Clima: $(x)$ sol ( ) chuva ( ) molhado \\
\hline Trecho & $\begin{array}{l}\text { DISTÂNCIAs } \\
\text { parciais }\end{array}$ & declividades & Observações \\
\hline \multirow{2}{*}{$0-1$} & 0 a $14 \mathrm{~m}$ & $5 \%$ & \\
\hline & 14 a $50 \mathrm{~m}$ & $10 \%$ & Aclive com pedras soltas \\
\hline \multirow{3}{*}{$1-2$} & 0 a $30 m$ & $1 \%$ & \\
\hline & 30 a $45 \mathrm{~m}$ & $7 \%$ & Grande quantidade de raízes expostas \\
\hline & 45 a $50 m$ & $20 \%$ & $\begin{array}{l}\text { Colocação de corrimão e construção de } \\
\text { degraus no início da subida }\end{array}$ \\
\hline
\end{tabular}

Fonte: Os autores.

\section{b) impactos e manejo}

Para avaliar os impactos na trilha, decorrentes do uso público, e as técnicas de manejo necessárias para a redução desses impactos, e avaliar quais as estruturas facilitadoras necessárias à visitação, foi elaborado um instrumento (Quadro 3) baseado em Lobo e Simões (2009); Secretaria de Meio Ambiente (2009) e Lechner (2006).

Os parâmetros de impacto avaliados foram: danos aos recursos naturais (quebra de galhos, inscrições em árvores, plantas pisoteadas fora da trilha, vandalismo e queimadas); danos à infraestrutura (pichação, remoção de estruturas, vandalismo); número de trilhas não oficiais; problemas de drenagem (empoçamentos, falta de sistema de drenagem, falta de manutenção nas 
canaletas/sistema de drenagem); erosão; presença de lixo e locais com necessidade de manejo.

Quadro 3: Instrumento utilizado na avaliação de impactos e necessidades de técnicas de manejo.

\begin{tabular}{|c|c|c|c|c|}
\hline \multicolumn{5}{|c|}{ LEVANTAMENTO DE impactos e necessidades de manejo DE TRILHA } \\
\hline \multirow{2}{*}{\multicolumn{2}{|c|}{$\begin{array}{c}\text { Local: Parna Viruá } \\
\text { Avaliador: }\end{array}$}} & \multicolumn{2}{|c|}{ Trilha: Acesso Grade } & Ficha $\mathbf{n}^{\circ}$ : \\
\hline & & \multirow{2}{*}{$\begin{array}{c}\text { Data: } \\
\text { MANEJO E } \\
\text { DISTÂNCIA } \\
\text { PARCIAL }\end{array}$} & \multicolumn{2}{|c|}{ Clima: ( $x$ ) sol ( ) chuva ( ) molhado } \\
\hline TRECHO & $\begin{array}{l}\text { IMPACTO E } \\
\text { DISTÂNCIA } \\
\text { PARCIAL }\end{array}$ & & OBSERVAÇÕES & COORDENADA \\
\hline \multirow{3}{*}{$0-1$} & I1 - 10m & M1 - 10m & $\begin{array}{l}\text { Empoçamento: elaborar um sistema } \\
\text { de drenagem, possivelmente barras } \\
\text { transversais, com escoamento } \\
\text { direcionado para a margem direita. }\end{array}$ & $\begin{array}{c}20 \text { N } 722192 \\
164850\end{array}$ \\
\hline & I2 - $28 m$ & $M 2-28 m$ & Erosão & $\begin{array}{c}20 N 722153 \\
164851 \\
\end{array}$ \\
\hline & - & M3 - 45m & $\begin{array}{c}\text { Falta de sinalização: incluir uma } \\
\text { placa de sinalização de direção para } \\
\text { a esquerda. }\end{array}$ & $\begin{array}{c}20 \text { N } 722102 \\
164857\end{array}$ \\
\hline
\end{tabular}

Fonte: Adaptado de Lobo e Simões (2009); Secretaria de Meio Ambiente (2009) e Lechner (2006).

Os locais identificados com algum tipo de impacto ou necessidade de manejo foram marcados com GPS e identificados na ficha de avaliação, com sua respectiva distância, a partir do ponto inicial do trecho. Para identificar os pontos na trilha, foram utilizadas etiquetas com cor vermelha que ficaram presas nas árvores para sinalizar um possível manejo da trilha.

\section{RESULTADOS E DISCUSSÃO}

A trilha estudada é classificada como linear, pois o visitante sai de um ponto a outro e retorna ao primeiro pelo mesmo caminho. Esse, geralmente, é o formato de trilha mais comum. Seu objetivo é conectar o caminho principal a algum destino, como lagos, mirantes, cavernas ou picos, entre outros (ANDRADE, 2008). Essa é a principal trilha do PNV, pois é a que acessa a grade de pesquisa da UC. Seu comprimento é de 1200 metros e leva o visitante a um conjunto de $60 \mathrm{~km}$ de trilhas, chamado de "grade de pesquisa". Nesse ponto 
o acesso é limitado somente a pesquisadores (Figura 5). A grade de pesquisa é um sistema ordenado de trilhas, na qual os pesquisadores podem elaborar coletas de forma sistematizada.

A trilha possui características de ser plano ondulado (EMBRAPA, 2009) e pode ser utilizada para a observação e interpretação da flora e da fauna silvestre, visto que o local abriga uma grande quantidade de aves, já catalogadas, demonstrando assim grande potencial para o turismo de observação de aves.

Figura 5: Detalhe da trilha de acesso à grade de pesquisa da Unidade de Conservação.

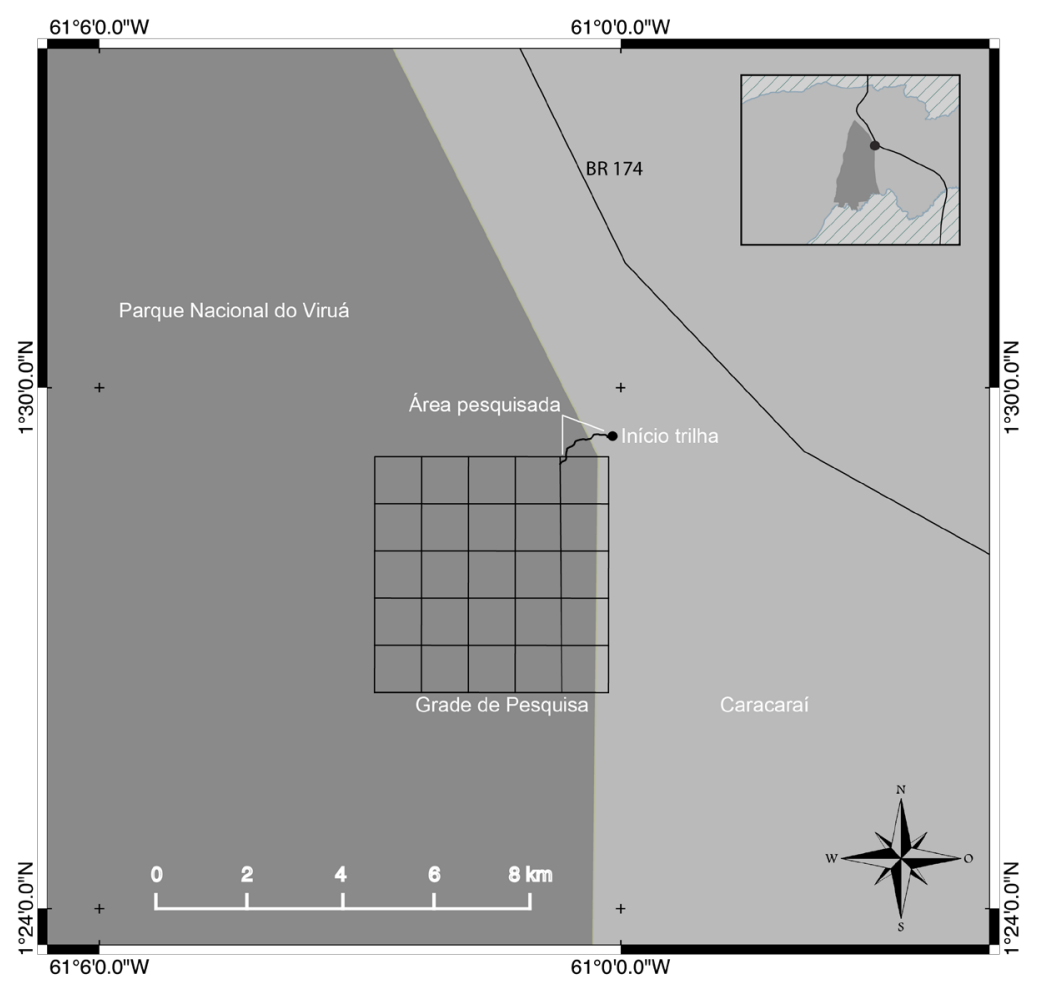

Fonte: Elaborada pelos autores com dados do IBGE e PN Viruá.

Com relação ao grau de dificuldade, a trilha não apresenta um grau elevado, visto que não apresenta subidas íngremes e não possui obstáculos que dificultem a caminhada. O único elemento que pode dificultar a caminhada é o calor, pois dentro do bioma amazônico, o calor e a umidade são uma constante em qualquer período do ano.

\section{LARGURA, PROFUNDIDADE E DECLIVIDADE}

O parâmetro largura apresenta valores entre $57 \mathrm{~cm}$ a $122 \mathrm{~cm}$ no trecho mais largo (Figura 6), apresentando uma largura média de 92,60 cm. Em estudos semelhantes, Marion e Leung (2011) obtiveram uma média de 43,60cm de 
largura, por outro lado, Teixeira e Ahlert (2011) obtiveram uma largura média de $280 \mathrm{~cm}$.

Esses dados demonstram que, mesmo em trilhas com usos semelhantes (lazer e pesquisa), o parâmetro largura pode variar e, portanto, o monitoramento constante e o estabelecimento de limites, conforme as características do local, do público e do tipo de atividade realizada, são de grande importância para a manutenção e o correto manejo da trilha.

Figura 6: Gráfico com os pontos da trilha e suas respectivas larguras, destacam-se o limite máximo e a média aceitável determinados para essa trilha.

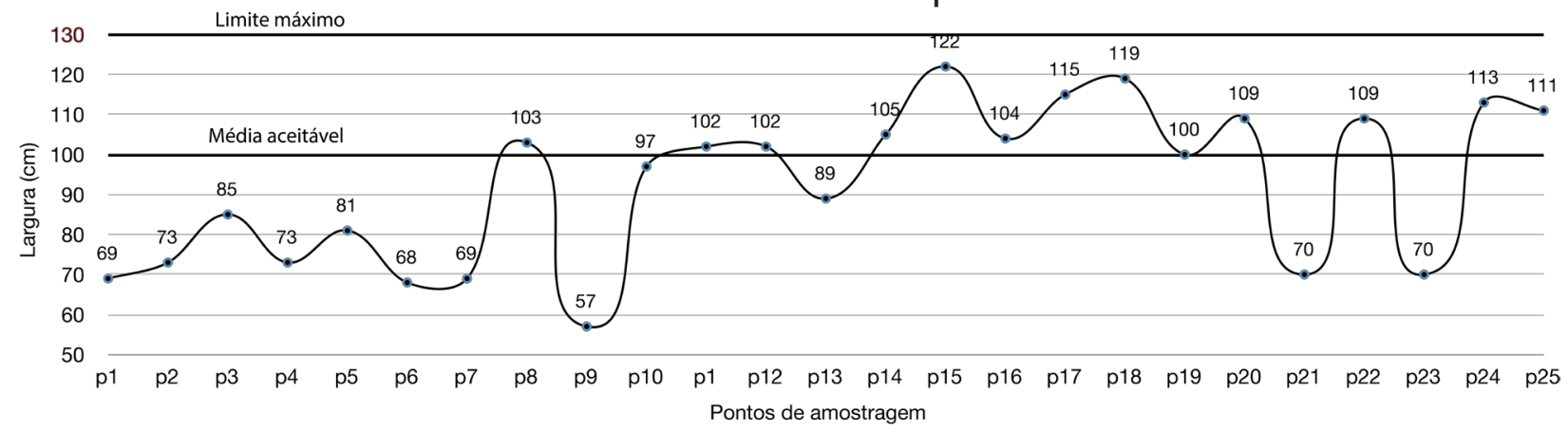

Fonte: Dados da pesquisa.

A largura da trilha é variável, dependendo diretamente do local, da vegetação e da forma que ela está sendo usada, entretanto se deve sempre pensar que quanto menor a largura, menor será o pisoteio e, consequentemente, menor será o impacto ambiental. Segundo Lechner (2006), o ideal é que a largura do piso das trilhas utilizadas por pedestres seja de 60 a 95cm. Já Nunes (1998) considera como sendo 1,45m um valor mais realista. Para Mitraud (2003), o limite aceitável de impacto em relação à largura da trilha é de 1,50m como trilha desenvolvida e de até $0,5 \mathrm{~m}$ de cada lado com impactos de visitação, desde que a cobertura do solo não seja eliminada. No local da pesquisa, foi adotado que o valor máximo de largura deverá ser de $1,30 \mathrm{~m}$, no entanto, a média geral da trilha não deverá passar de $1 \mathrm{~m}$.

Na trilha, os dados demonstram que os pontos: 15, 17, 18, 20, 22, 24 e 25 apresentam larguras que não ultrapassam à largura limite, contudo os valores estão acima da média estipulada. Cabe ressaltar que, em alguns desses locais, havia obstáculos, como galhadas, pequenas subidas, e pontos de alagamento, o que faz com que as pessoas que estão fazendo a trilha desviem e saiam do perímetro que deve ser pisado, causando assim o alargamento da trilha. 
Com relação à profundidade, os dados demonstram que existe uma variação de 4 a $10 \mathrm{~cm}$ nos pontos monitorados (Figura 7). Além disso, a profundidade média foi de 6,32cm, abaixo da encontrada por Marion e Leung (2011), que foi de 10,16 cm em estudo realizado no Smoky Mountains National Park (EUA) e de Nunes (2008), que foi de $30 \mathrm{~cm}$, em estudo realizado no Parque Estadual da Serra da Baitaca (Curitiba).

Figura 7: Gráfico com os pontos da trilha e suas respectivas profundidades, destacamse o limite máximo e a média aceitável determinados para essa trilha.

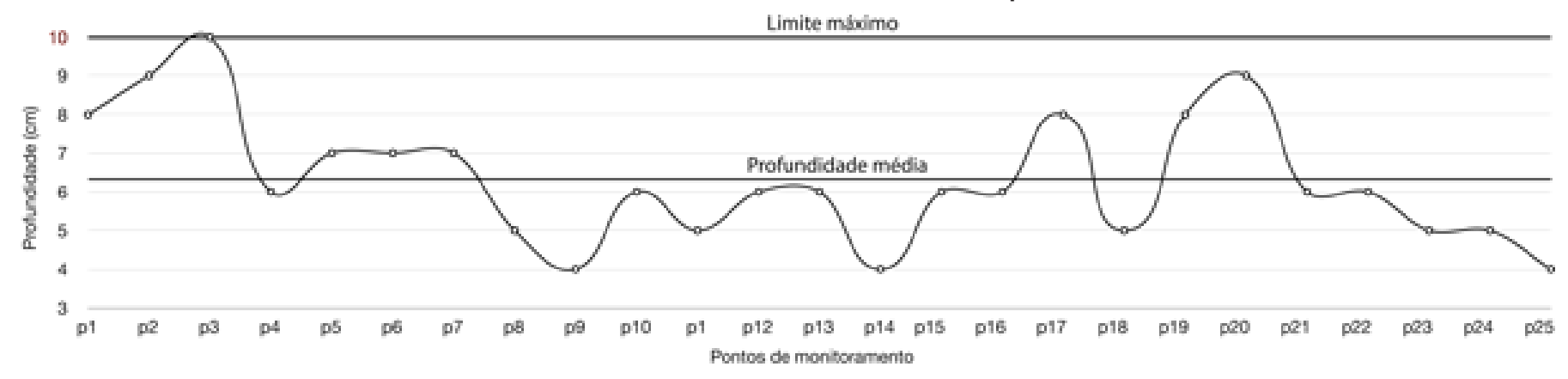

Fonte: Dados da pesquisa.

O estudo da profundidade do piso da trilha é um elemento importante, porque serve para determinar o nível de uso da trilha, pois com o uso constante, o solo tende a compactar, rebaixando o leito da trilha. Essa compactação, juntamente com os impactos na vegetação, pode aumentar a densidade e a resistência à penetração, mudanças na estrutura e estabilidade do solo, perda da camada orgânica, redução das taxas de infiltração, aceleração e aumento da erosão (HAMMIT \& COLE apud LOBO; SIMÕES, 2011).

Com relação à declividade, é uma variável que determinará o grau de dificuldade de uma trilha. Quanto mais inclinação o local apresentar, maior cuidado será necessário no planejamento da trilha quanto ao manejo da erosão, sendo que acima de 12 graus ou $20 \%$ é necessária a construção de escadas. Se o trecho for extenso, a trilha deve ser construída em ziguezague (ANDRADE, 2008). De acordo com a legislação ambiental, áreas com declividade acima de 45 graus ou 100\% são consideradas áreas de preservação permanente, não sendo permitidas intervenções (BRASIL, 2012).

No local da pesquisa foram identificados 3 trechos com declividade acima de $15 \%$ (Figura 8). O primeiro no trecho, 15-16, entre 10 a 26 metros $^{1}$ e 46 a 1 Essa distância é calculada a partir do ponto de controle, neste caso, o ponto 15. 
50, apresentou inclinações de 15\%. No trecho 16-17, na distância entre 0 e 30 metros, a declividade foi entre 10 a 20\%. E, finalmente, no trecho 22-23, na distância 10 a 32m a declividade foi de $26 \%$ e na distância 32 a 39m de 30\%.

Figura 8: Pontos da trilha e suas respectivas declividades, destacam-se o pontos acima de $15 \%$.

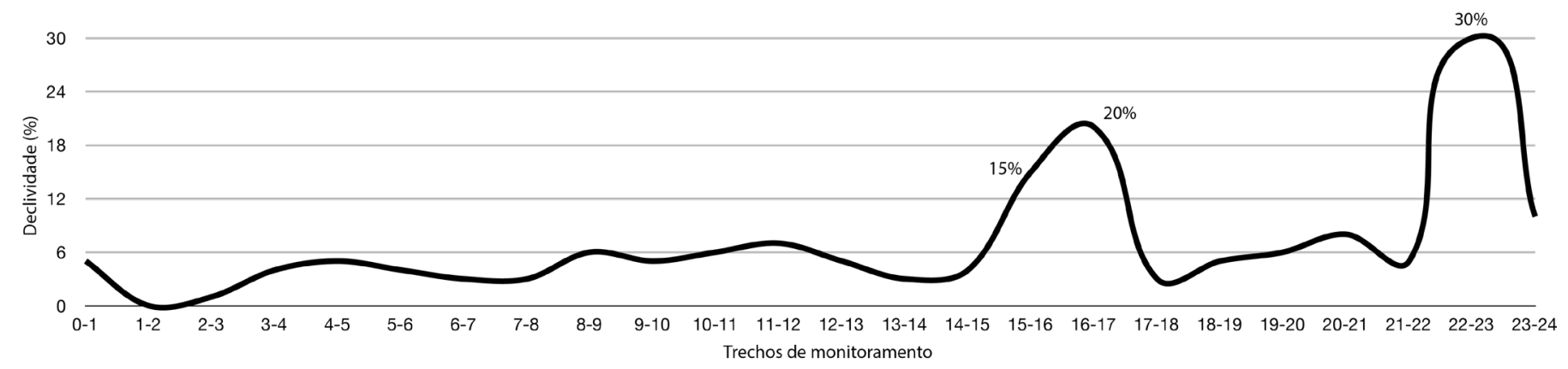

Fonte: Dados da pesquisa.

Para Mitraud (2003), a análise da inclinação é importante, pois uma trilha se torna suscetível à erosão de acordo com o tipo de solo, à declividade do terreno e ao tipo de atividade nela desenvolvida. Em casos de extrema declividade (mais de $20 \%$ ), deve-se estudar cuidadosamente a possibilidade de alterar o traçado proposto para a trilha, ou adequá-la com soluções técnicas construtivas.

IMPACTOS

A identificação de impactos ambientais e as sugestões de manejo foram mapeadas e o resultado foi um mapa da trilha com os locais que merecem destaque e atenção entre os gestores (Figura 9). O mapa apresenta uma análise detalhada das alterações necessárias para o adequado manejo da trilha, possibilitando o contato e a interpretação de importantes aspectos de sustentabilidade ambiental na percepção dos turistas que visitam o local.

Os impactos encontrados são decorrentes de ação natural, como queda de galhos e ação hídrica; por outro lado, os relacionados à ação antrópica são quase inexistentes. Essa característica pode ser relacionada aos fatores como perfil do visitante e à baixa frequência de visitas, quando comparado a trilhas em outras UCs do Brasil.

Figura 9: Mapa da trilha com respectivos pontos de impacto e manejo. 


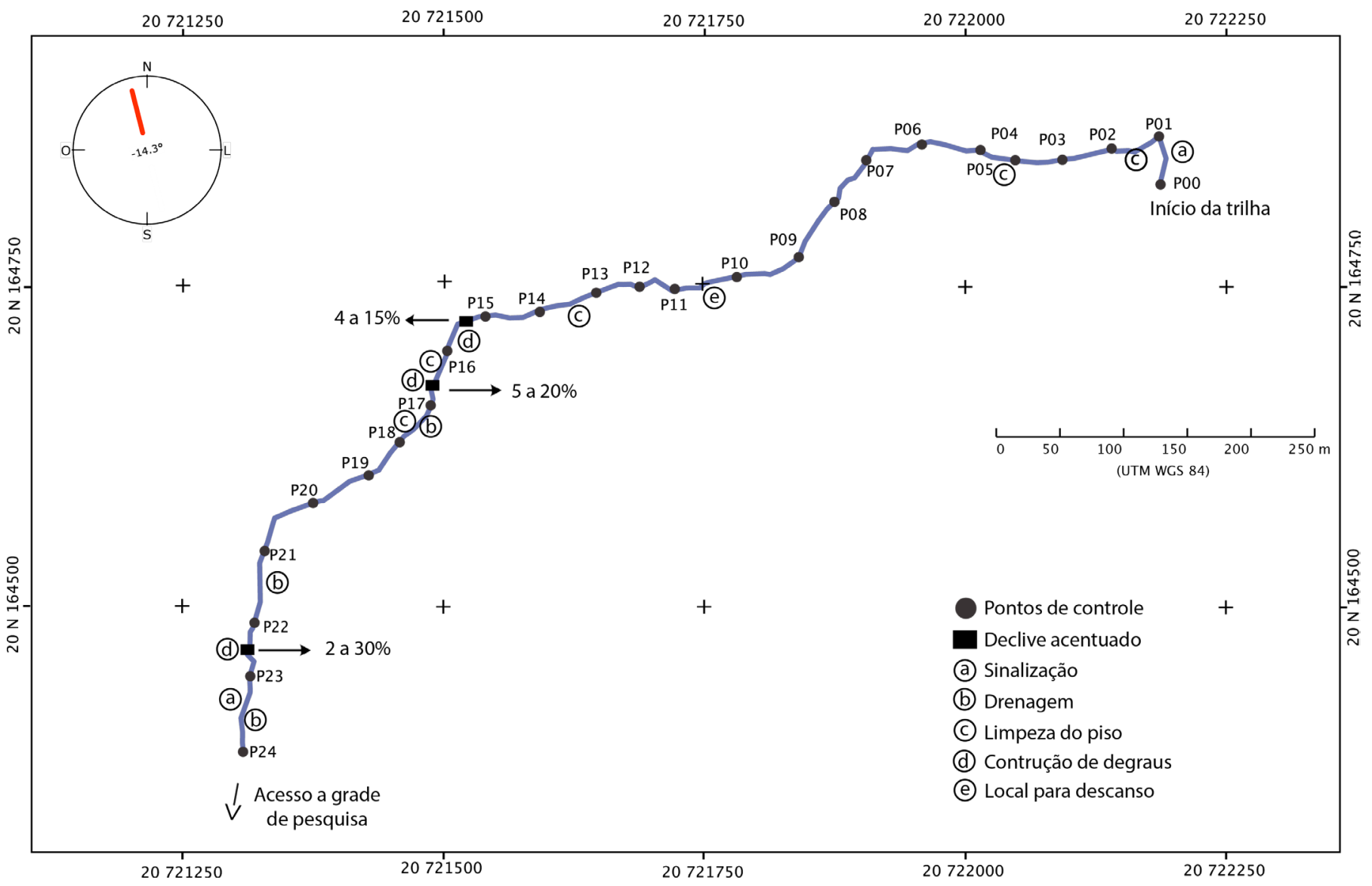

Fonte: Dados da pesquisa.

Segundo a análise do livro de registro de visitantes do Parque, o perfil de público que frequenta o local está concentrado principalmente em pesquisadores e visitas técnicas de escolas e universidades, isso contribui para um maior controle dos impactos, uma vez que se trata de um público com objetivos de pesquisa ou educação ambiental. Outro fator é que o PNV ainda não recebe um número considerável de visitantes para turismo. A baixa procura do local pela comunidade como forma de lazer se deve a uma resistência e a um desconhecimento da comunidade que a área é aberta para visitas.

\section{TÉCNICAS DE MANEJO}

Essa etapa se refere à elaboração de um diagnóstico dos pontos que necessitam de algum tipo de manejo, como construção de estruturas de drenagem, guarda-corpo, sobreposição de corpos d’água, assim como locais de descanso, contemplação e interpretação ambiental.

Com relação ao indicador largura, apesar da trilha apresentar uma média de $92,6 \mathrm{~cm}$, sendo que $100 \mathrm{~cm}$ foi considerado o ideal, verificou-se que em $48 \%$ 
dos pontos de amontragem a largura é superior a $100 \mathrm{~cm}$. Esses dados indicam a necessidade de técnicas de manejo para adequar a trilha aos parâmetros adequados. Sugere-se o uso de barreiras de contenção para a lateral da trilha. Essa técnica baliza a caminhada do visitante, pois alerta o mesmo onde são os limites de sua caminhada. Além disso, faz com que o piso da trilha se mantenha estável, uma vez que esses balizadores servem como barreira de proteção de eventuais deslizamentos. As barreiras de contenção servem para manter o piso da trilha em condições de caminhada, pois mantêm a camada superior (serrapilheira ou cascalho) no lugar, auxiliando no sistema de drenagem.

Como a trilha altera o padrão de circulação de água no solo, algumas obras de reorganização da drenagem são necessárias. Verificou-se que o sistema de drenagem da trilha em alguns trechos é ineficiente, pois não há uma técnica de manejo aplicada. Verificou-se que, nos trechos 17-18, 21-22 e 23-24, há necessidade de elaboração de sistemas de drenagem em razão do acúmulo de água da chuva, pois são áreas com piso levemente rebaixado.

A colocação de fatias de troncos ou pedras (Figura 10) auxiliaria na caminhada em dias de chuva ou períodos de concentração de água no local. Pode-se, ainda, construir canais laterais de escoamento, canais que cruzam perpendicularmente ou diagonalmente a trilha (tanto em nível, quanto por baixo da mesma) e valas ou barreiras oblíquas à superfície da trilha, para facilitar o escoamento da água. Outra maneira, porém mais dispendiosa, são tablados ou trilhas suspensas, que permitem uma caminhada fácil e segura, transferindo a superfície de uso direto do solo para a madeira.

Figura 10: Técnica de manejo para a travessia de áreas alagadas

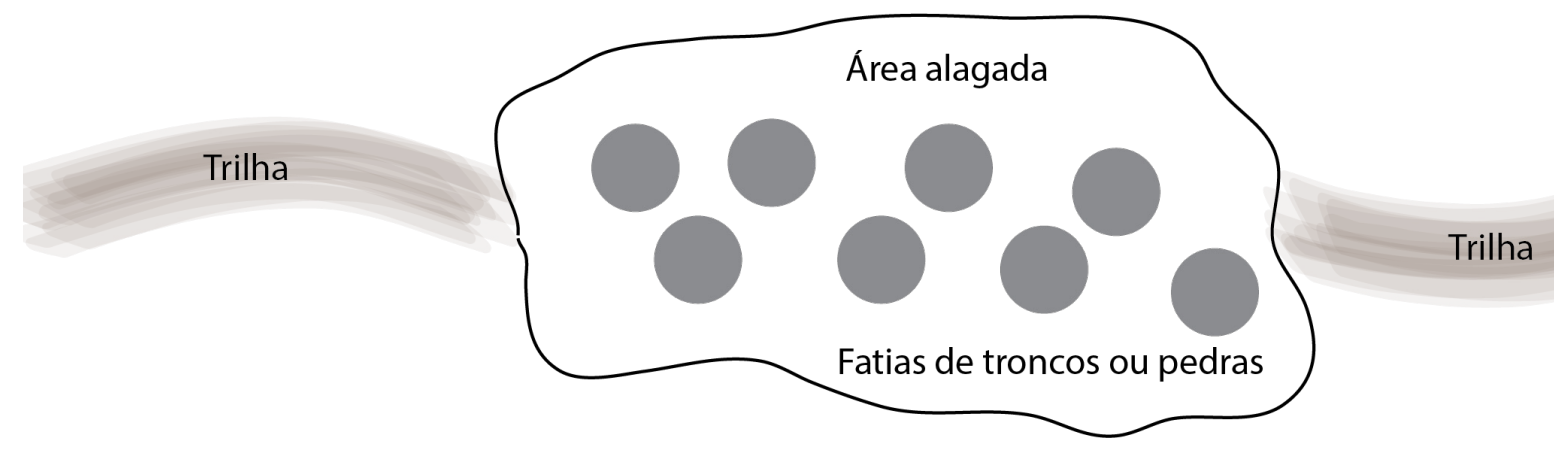

Fonte: Adaptado de Andrade, 2008.

Placas são tipicamente usadas para identificar o começo de uma trilha ou indicar as diferentes trilhas que dali partem. No local da pesquisa, verificouse a falta de sinalização, tanto no início, quanto em trechos chaves da trilha, 
o que pode causar dúvidas ao visitante, devendo ser instalada nos locais identificados. As placas também são usadas nas conexões e nas bifurcações, identificando cada uma pelo nome e indicando sua direção. Placas também podem identificar atrativos (mirantes, cachoeiras), destinos, interpretação de flora e, ocasionalmente, regulamentos, avisos ou impedimentos (SECRETARIA DE MEIO AMBIENTE, 2009).

Sugere-se a instalação de uma placa no início da trilha, contendo todas informações necessárias ao visitante, como: tempo e distância da caminhada, informações de segurança e normas gerais de conduta, além de outras informações que se julguem necessárias (Figura 11). Além disso, a instalação de placas contemplando aspectos de interpretação ambiental auxiliariam no processo de educação ambiental do Parque.

Figura 11: Sugestão de instalação de placa de início da trilha.

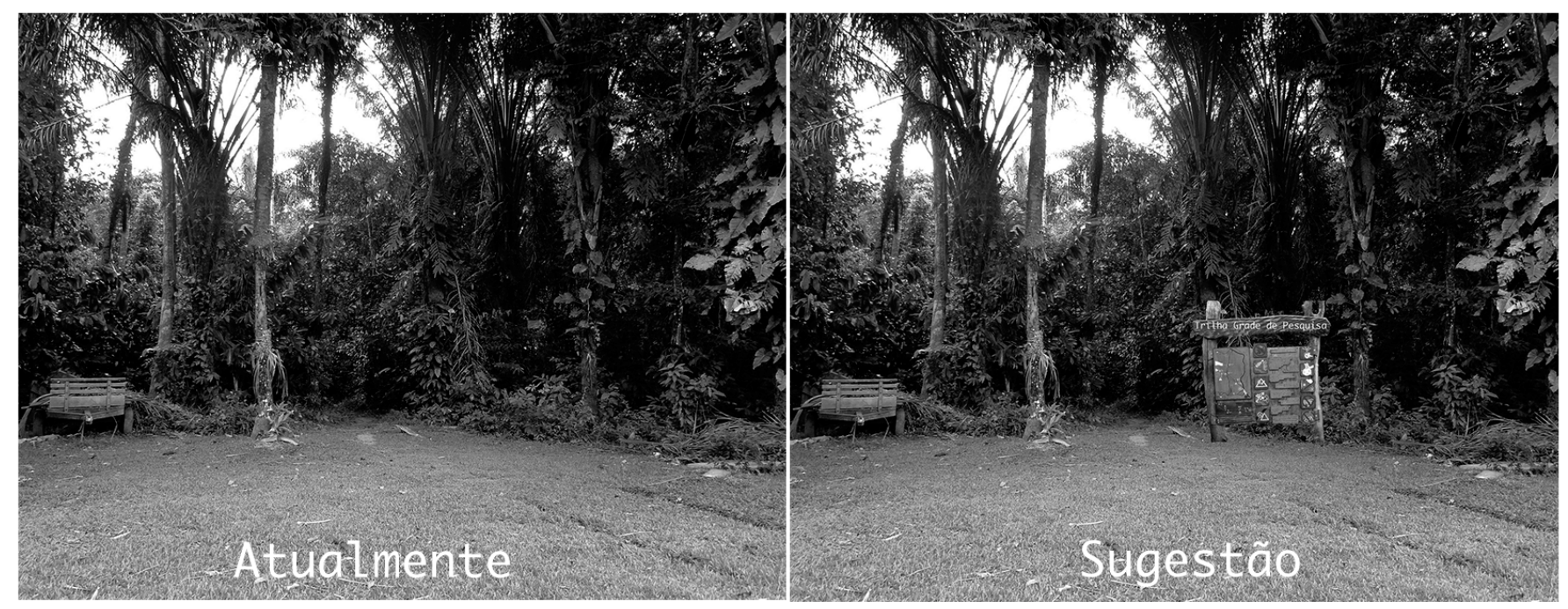

Fonte: os autores

Com relação à limpeza da trilha, foram verificados alguns trechos que necessitam de manutenção, pois apresentam grande quantidade de galhos, troncos e rochas expostas. Esses materiais obstruem a livre circulação do visitante, lembrando que caso haja muitos galhos, o visitante poderá escolher um trajeto mais fácil, criando um atalho ou trilha secundária.

Juntamente com a limpeza da trilhas, as irregularidades do terreno deixam a trilha desconfortável e sem segurança. Regularizar o piso consiste em eliminar grandes saliências e depressões, ou até mesmo adequar a inclinação do piso para orientação da drenagem. A adequação do seu traçado, no que diz respeito à inclinação, é fundamental em todas as trilhas, principalmente quando a trilha é em ambiente de muitos declives. 
Quando o leito da trilha apresenta uma inclinação igual ou superior a $12 \%$, é indispensável seu reordenamento, seja através da suavidade de um novo traçado em seu percurso até a construção de degraus ou escadas. Como a trilha em estudo já existe, a criação de um novo traçado seria causadora de um maior impacto, nesse caso, a técnica de manejo a ser utilizada seria a construção de degraus. Nos trechos 15-16 e 22-23, caracterizados como os de maior declividade, podendo chegar a 30\%, faz-se necessária a construção de degraus e instalação de corrimão para facilitar tanto a subida, quanto a descida desses trechos, bem como evitar problemas de erosão e exposição de raízes devido ao fluxo de visitantes no local (Figura 12).

Figura 12: Sugestão de instalação de degraus na trilha.
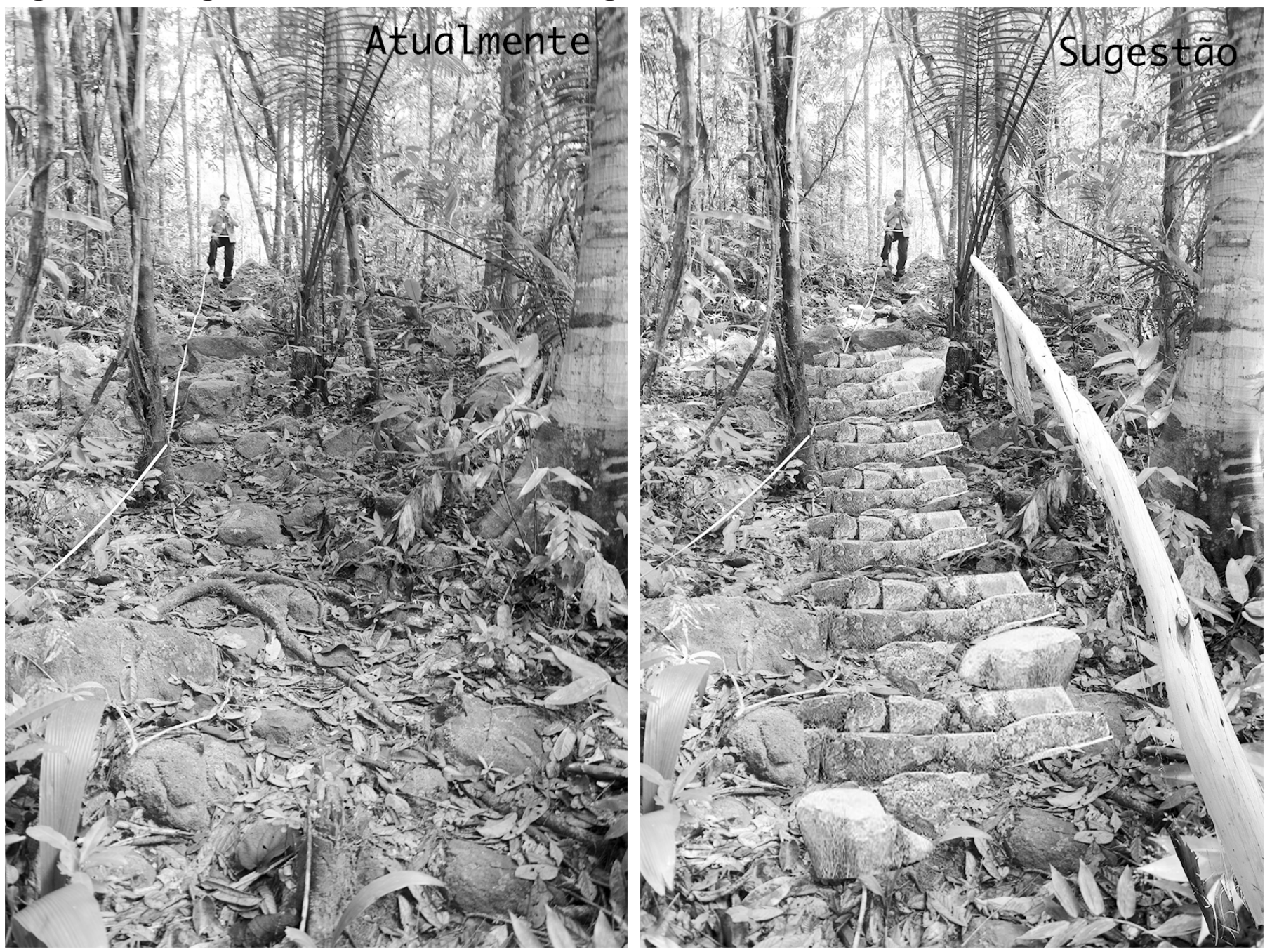

Fonte: Os autores

Considerando que a trilha do Viruá possui um trajeto de $1200 \mathrm{~m}$, faz-se necessário um ponto para descanso, pois se deve prever que o perfil de público que visitará o local pode ser o mais variado, além disso, cada pessoa possui condições físicas diferenciadas. Dessa forma, no trecho 10-11 já existe um 
espaço para parada. Como técnica de manejo, sugere-se a instalação de bancos para descanso e contemplação do ambiente, uma placa com informações da trilha e uma lixeira.

Por meio desses manejos a trilha pode ser utilizada mais facilmente pelos visitantes e também contribuirá para uma redução nos impactos que a visitação pode causar ao local. Vale ressaltar que um trabalho de educação e interpretação ambiental podem contribuir consideravelmente para o desenvolvimento da atividade turística de forma responsável no Parque.

\section{CONSIDERAÇÕES FINAIS}

Considerando a importância dos recursos naturais, principalmente em se tratando do bioma amazônico, todas as atividades que se utilizam desses recursos para o seu desenvolvimento devem fazê-lo de forma responsável. 0 turismo realizado em ambientes naturais faz parte dessas atividades e, como tal, deve ser realizado de forma responsável, visando ao desenvolvimento adequado da atividade no ambiente natural com objetivo de contribuir na preservação e não na degradação.

Com objetivo de desenvolver a atividade turística no Parque de forma a evitar a degradação da trilha, essa etapa da pesquisa se refere à elaboração de um diagnóstico dos pontos que necessitam de algum tipo de manejo para que a trilha possa ser aberta à visitação turística sem causar impactos irreversíveis ao local. Conforme o estudo, pode-se perceber que existem diversos pontos que necessitam de alguma intervenção para que a trilha possa ser realizada de forma segura tanto aos visitantes quanto ao ambiente.

Destacam-se como os principais manejos a serem realizados para a utilização turística responsável: a instalação de placas de sinalização, a construção de degraus e de corrimões nos trechos de declividade elevada, e a aplicação das técnicas para os trechos alagados. Vale ressaltar que o clima amazônico tem um longo período de seca e um longo período de chuvas, sem esse manejo a trilha não poderia ser utilizada pelos visitantes no período chuvoso sem gerar impactos negativos ao local. Além disso, existem cuidados que devem ser 
ISSN: 1983-7151

constantes quanto à manutenção da trilha, como a questão da limpeza de piso e galhos.

Em se tratando de uma trilha para utilização tanto de turismo quanto de pesquisa, o monitoramento dos impactos que essas atividades podem gerar no local são de fundamental importância para que a utilização ocorra de forma responsável. Sendo assim, esse se caracteriza como o primeiro estudo, devendo ser desenvolvidos novos estudos e pesquisas no local, como estudo da capacidade de carga da trilha, objetivando o desenvolvimento responsável do turismo no Parque Nacional do Viruá.

\section{REFERÊNCIAS}

ANDRADE, W. J. (2003) Implantação e manejo de trilhas. In: MITRAUD, Sylvia (Org.). "Manual de ecoturismo de base comunitária: ferramentas para um planejamento responsável." Brasília: WWF Brasil.

ANDRADE, Waldir Joel de. (2008). "Manejo de trilhas: um manual para gestores." São Paulo: Instituto Florestal.

BRASIL. Lei n 12.615, de 25 de maio de 2012 (2012). “Dispõe sobre a proteção da vegetação nativa". Diário Oficial da República Federativa do Brasil. Brasília, DF.

CPRM. (2002). "Zoneamento ecológico-econômico da região central do Estado de Roraima." Ministério de Minas e Energia.

EMBRAPA - Centro Nacional de Pesquisas do Solo. (2009). "Sistema Brasileiro de classificação do solo." Rio de janeiro, Embrapa.

FERRETTI, E. R. (2002). „Turismo e meio ambiente: uma abordagem integrada.” São Paulo: Roca.

FEARNSIDE, Philip M. (2006). "Desmatamento na Amazônia: dinâmica, impactos e controle." Revista ACTA Amazônica, 36, 395-400.

ICMBIO - Instituto Chico Mendes de Conservação da Biodiversidade. (2010). "Projeto de Ampliação do Parque Nacional do Viruá". Brasília, Icmbio.

INSTITUTO FLORESTAL. (2008). "Manejo de trilhas: manual para gestores." Série Registros, n. 35, São Paulo, Secretaria do Meio Ambiente.

LECHNER, L. (2006). „Planejamento, implantação e manejo de trilhas em unidades de conservação". Fundação O Boticário de Proteção à Natureza. Cadernos de Conservação, ano 3, n.3, junho 2006. 
LOBO, A. C.; SIMÕES, L. L. (2009). "Manual de Monitoramento e Gestão dos Impactos da Visitação em Unidades de Conservação". São Paulo: Secretaria de Meio Ambiente.

MARION, Jeffrey L.; LEUNG, Yo-Fai. (2011). "Trail Resource Impacts and An Examination of Alternative Assessment Techniques." Journal of Park and Recreation Administration, 19 (3), 17-37.

MITRAUD, Sylvia F. (2001). „Uso recreativo do Parque Nacional Marinho de Fernando de Noronha: um exemplo de planejamento e implementação." WWF Brasil: Brasilia.

MITRAUD, S. (2003). „Monitoramento e controle de impactos de visitação." En MITRAUD, S. Manual de ecoturismo de base comunitária: ferramentas para um planejamento responsável. Brasília: WWF Brasil.

NUNES, Tiago; MATHEUS, R. Briones; STRUMINSKI, Edson. (2008). "Monitoramento e avaliação da largura e profundidade da trilha da asa delta, Morro do Anhangava - PR". Revista Caminhos da Geografia, v. 9, n. 27. Uberlândia: Setembro.

RODRIGUES, Adyr Balastreri. (2003). "Patrimonio, territorio y emprendedorismo: pilares del desarrollo del turismo en base local". Aportes y Transferencias, v. 2, ano 7. Universidad Nacional de Mar del Plata: Mar del Plata, Argentina.

RUDZEWICZ, Laura; PEREIRA, Renata; LANZER, Rosane M.; TEIXEIRA, Paulo. R.; SBERCI, F.; SHAFER, A. E. (2009). "Interfaces entre Geoprocessamento e Turismo: o estudo de caso do Projeto Lagoas Costeiras no Litoral Médio e Sul do RS". In: Anais do Seminário da Associação Brasileira de Pesquisa e Pós-Graduação em Turismo. São Paulo, Universidade Anhembi Morumbi.

RUSCHMANN, Dóris. (2003). "Turismo e planejamento sustentável: a proteção do meio ambiente". Campinas: Papirus.

SECRETARIA DE MEIO AMBIENTE. (2009). "Manual de construção e manutenção de trilhas". São Paulo: Instituto Florestal.

TEIXEIRA, Paulo Roberto; AHLERT, Siclério. (2011). "O uso de geotecnologias na análise dos impactos ambientais no Salto Ventoso - Farroupilha/RS". Revista Brasileira de Pesquisa em Turismo, v.5, n.3, p.309-324.

\section{CONTRIBUIÇÃO DOS AUTORES NA CONSTRUÇÃO DO ARTIGO}

TEIXEIRA: Pesquisa de campo; fundamentação teórica; descrição da área de estudo; definição da metodologia; cálculos e imagens; resultados e discussão; revisão das considerações finais. 
ISSN: 1983-7151

MICHELIN: Pesquisa de campo; fundamentação teórica; resumo; revisão dos cálculos; resultados e discussão; considerações finais. 